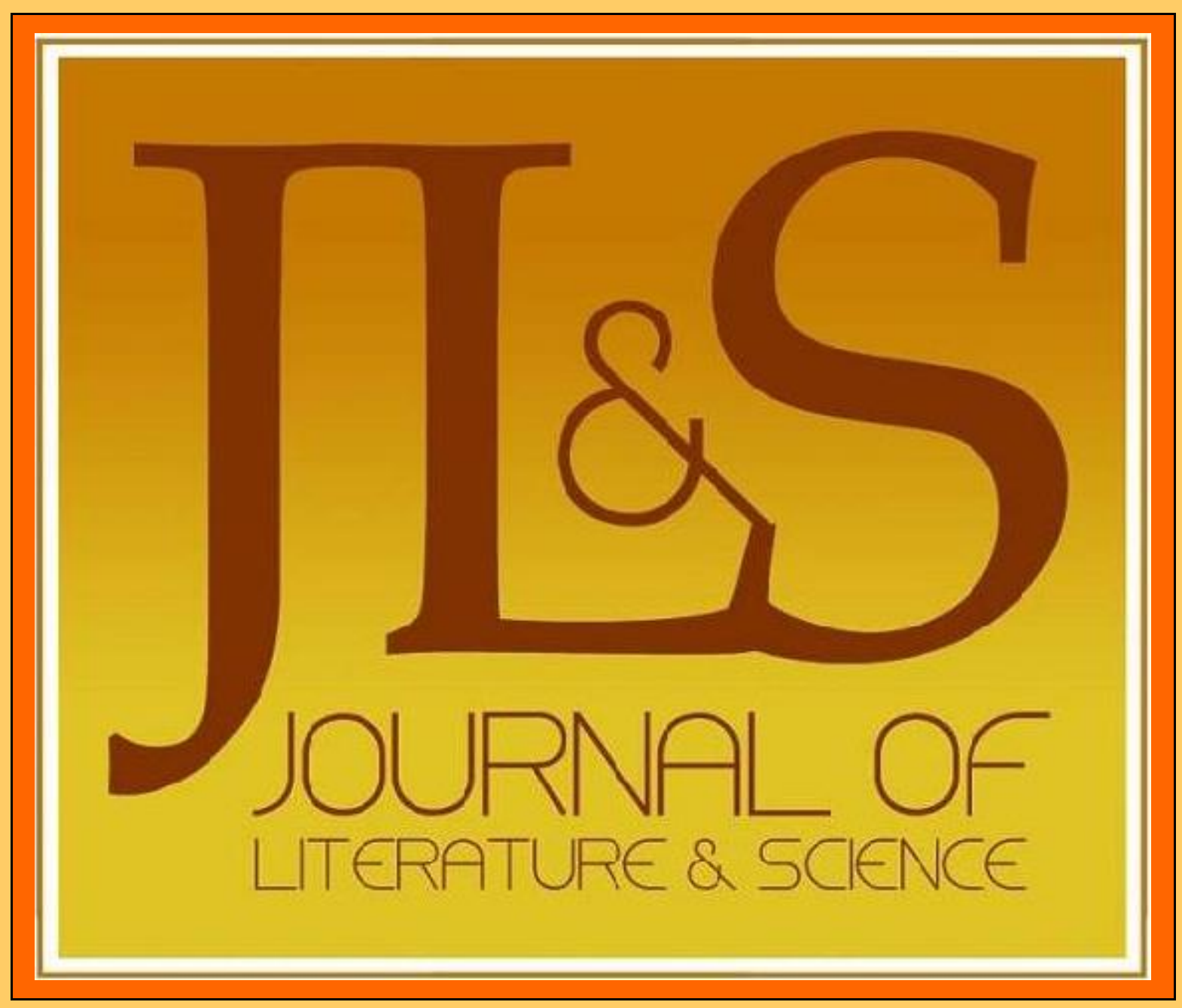

Volume 10, Number 1 (2017) 


\section{STATE OF THE UNIONS}

SPECIAL JOINT ISSUE WITH CONFIGURATIONS: PART 1

Melissa Littlefield \& Martin Willis

Introduction: The State of the Unions

Thinking Through Disciplinary History

5

John Holmes

Consilience Rebalanced: Edward O. Wilson on Science, the Humanities and the Meaning of Human Existence

Laura Otis

Thirty Years of Interdisciplinary Research: The Future Promise of SLSA

15

Darren N. Wagner and Joanna Wharton

Literature and Science in Eighteenth-Century Studies: Mountain Gloom or Mountain Glory?

Mapping Territories

21

Derek Lee

On Anarchy, or What We Talk About When We Talk About Science

26

Jennifer L. Lieberman

Finding a Place for Technology

32

Kanta Dihal

On Science Fiction As a Separate Field

Ralph O'Connor

The Meanings of 'Literature' and the Place of Modern Scientific Nonfiction in Literature and Science

Life in the Zooniverse: Working with Citizen Science 
Action Items

52

Susan Merrill Squier

Extreme Citizen Literature, Science, and the Arts: A Comic Proposal for our Fields

58

Abigail Droge

Teaching Literature and Science in Silicon Valley

65

Jay A. Labinger

Where are the Scientists in Literature and Science?

70

Richard Nash

A Sense of Belonging: The Place of Literature and Science in a More Ecologically Alert Academy

75

Cary Wolfe

'Theory,' the Humanities, and the Sciences:

Disciplinary and Institutional Settings

Article Reviews

81

Fani Cettl

Review of Melissa Bailes's “The Psychologization of Geological Catastrophe in Mary Shelly's The Last Man."

83

Ben De Bruyn

Review of Julie A Smith's “Representing Animal Minds in Early Animal Autobiography: Charlotte Tucker's The Rambles of a Rat and NineteenthCentury Natural History." 
85

Roger Ebbatson

Review of Jesse Oak Taylor's “Tennyson's Elegy for the Anthropocene: Genre, Form and Species Being."

87

Jayne Thomas

Review of Jill Marie Treftz's "Tennysons The Princess and the Culture of Collection."

89

Jo Waugh

Review of Ross G. Forman's "A Parasite For Sore Eyes: Rereading Infection Metaphors in Bram Stoker's Dracula." 
The Journal of Literature and Science (JLS) is a peer-reviewed academic journal published twice annually in Summer and Winter. The JLS was founded in 2007, and produced its first issue at the beginning of 2008. It was originally hosted by the University of Glamorgan's Research Centre for Literature, Arts and Science (2007-12), before moving to its own independent online site in March 2013, with the support of the University of Westminster. The journal's first, and present, editor is Professor Martin Willis, Professor of English at Cardiff University. The Advisory Board includes leading scholars of literature and science from around the world. The JLS is published in digital format, is entirely open access, and requires no subscription fee.

The journal is dedicated to the publication of academic essays on the subject of literature and science, broadly defined. Essays on the major forms of literary and artistic endeavour are welcome (the novel, short fiction, poetry, drama, periodical literature, visual art, sculpture, radio, film and television). The journal encourages submissions from all periods of literary and artistic history since the Scientific Revolution; from the Renaissance to the present day. The journal also encourages a broad definition of 'science': encapsulating both the history and philosophy of science and those sciences regarded as either mainstream or marginal within their own, or our, historical moment. However, the journal does not generally publish work on the social sciences. Within these confines, essays submitted to the journal may focus on the literary and scientific productions of any nation or group.

All essays should be interdisciplinary in focus, offering an original view of both the literary or artistic subject matter and the science or sciences under consideration. While essays on individual examples of literary and artistic production are welcomed, these should also seek to show the wider significance of their analyses and interpretations. The journal does not publish essays focused exclusively on literature or art, or exclusively on the history and philosophy of science.

\section{Submission and Citation Information}

Abstracts and articles for submission should be sent to the Editor, Professor Martin Willis, by email only: WillisM8@cardiff.ac.uk

The $J L S$ recommends that an initial email inquiry, including an abstract of the proposed article, should be sent in advance of completed articles in order to ensure that the subject matter is suitable for publication under the $J L S$ ’s remit.

All articles should be from 6000-9000 words in length, interdisciplinary in focus, and offering an original view of both the literary or artistic subject matter and the science or sciences under consideration. While articles on individual examples of literary and artistic production are welcomed, these should also seek to show the wider significance of their analyses and interpretations. The journal does not publish essays focused exclusively on literature or art, or exclusively on the history and philosophy of science.

All submitted articles should be presented in MLA Style, with notes kept to a minimum. JLS articles do not use personal pronouns (e.g. "In this article I will..." is not appropriate, while "This article will..." is appropriate). All spellings should follow British English. All submitted articles should include a short abstract (150 words maximum) below the title and author's name and ahead of the opening sentence.

The $J L S$ aims to complete the first stage of peer review (consideration of articles by the editor and advisory board) within 4 weeks of submission and the second stage of peer review (external, blind, double peerreview) within 8 weeks of the completion of the first stage. All authors whose articles reach the second stage of peer review should expect to have a decision on publication within approximately 12 weeks of the date of their original submission of an article

Citing the JLS: the journal's full title is the Journal of Literature and Science, and its first issue was Volume 1, Number 1 (2007). All page numbers to individual essays can be found when accessing the PDF file of that essay. The journal's ISSN is 1754-646X. Citations should give Author, 'Title,' Journal of Literature and Science Vol, No. (Year): pp., organized according to the specific style guide being used. 
The Journal of Literature and Science is committed to real and immediate open access for academic work. All of the $J L S$ 's articles and reviews are free to access immediately from the date of publication. There are no author charges (commonly known as APCs) prior to publication, and no charge for any reader to download articles and reviews for their own scholarly use. The JLS does not, therefore, operate either a Gold or Green model of open access, but is free to all at any time and in perpetuity. To facilitate this the $J L S$ depends upon the financial underwriting provided by the University of Westminster's Department of English, the goodwill of its editorial team and advisory board, and the continuing support of its network of peer reviewers.

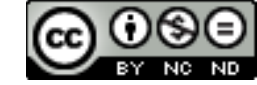

The Journal of Literature and Science also operates under the Creative Commons Licence CC-BY-NC-ND. This allows for the reproduction of articles, free of charge, for non-commercial use only and with the appropriate citation information. All authors publishing with the $J L S$ accept these as the terms of publication. Please note that copyright of the content of all articles and reviews remains with the designated author of the article or review. Copyright of the layout and design of $J L S$ articles and reviews remains with the Journal of Literature and Science and cannot be used in other publications.

The JLS is a member of PILA (Publishers International Linking Association) and submits all articles and reviews, including all works that these cite, to CrossRef for cross-referral. To find JLS articles and reviews via their DOI numbers, use the URL http://dx.doi.org/[DOI number]

\section{Reviews}

The JLS reviews articles on literature and science, or relevant articles in cognate fields such as the history of science, cultural studies or sociology, published in academic journals within the last twelve to eighteen months. Reviews are generally commissioned by the Reviews Editor, but potential contributors are encouraged to contact the Reviews Editor to suggest articles for review.

The JLS does not, at any time, review books or collections of essays. The editors take the view that books within the field are already well covered by reviewing journals while journal articles, often the publication type that offers the most recent scholarship, are never considered in review processes. By doing so, the JLS hopes to offer its readers access to academic dialogue on the most recent advances in literature and science.

Reviews should be approximately 750 words in length, should follow MLA Style (notes generally not allowed), and should aim to describe the content of the article under review as well as offer an analysis of its strengths and weaknesses and conclude by assessing its significance for literature and science scholarship.

Proposals for review and completed reviews should be sent to the Reviews Editor, Dr Michelle Geric by email only: m.geric@westminster.ac.uk

\section{Editorial Board}

Editor: Martin Willis

Reviews Editor: Michelle Geric

Editorial Assistants: Rebecca Spear \& Jim Scown

Advisory Board: Tim Armstrong, Gowan Dawson, Folkert Degenring, John Holmes, Lisa Hopkins, William Hughes, Kelly Hurley, Meegan Kennedy, Leah Knight, Sharon Ruston, Eleanor Sandry, Jonathan Sawday, Carol A. Senf, Andrew Smith, Laurence Talairach-Vielmas, Jeff Wallace, Alexandra Warwick and Catherine Wynne.

Web design: Martin Callanan

Logo: Joel Cooper 
Fani Cettl is completing her doctoral thesis at the Department of Gender Studies, Central European University, on politics between the human and the non-human in the Gothic science fictions of M. Shelley and H. G. Wells. She has published recently on the biopolitics of The Hunger Games.

Ben De Bruyn is associate professor of comparative literature at Maastricht University. He is the author of Wolfgang Iser. A Companion (De Gruyter, 2012) and co-editor of Literature Now. Key Terms and Methods for Literary History (Edinburgh UP, 2016). In addition, he has published on literature and the environment in journals including Studies in the Novel and Oxford Literary Review.

Kanta Dihal is a third-year doctoral researcher and tutor at St Anne's College, University of Oxford, funded by the Iris Murdoch Graduate Research Scholarship. Her thesis, titled The Stories of Quantum Physics, is supervised by Professor Sally Shuttleworth and Dr Michael Whitworth. Her research intersects the fields of science communication, literature and science, and science fiction. She is a co-organiser of the AI Narratives project at the Centre for the Future of Intelligence, University of Cambridge. She is also the Literature Editor of The Oxford Culture Review.

Abigail Droge is a $\mathrm{PhD}$ candidate in English Literature at Stanford University, with a focus in Victorian literature. She holds a BA from Yale. In her dissertation, she investigates the politics of literacy in the nineteenth and twenty-first centuries and is committed to bringing research and teaching together in the same conversation. Her project is largely shaped by the experience of being a humanist in the science-andtech-centered environment of Silicon Valley, California. Her work has recently appeared in the Victorian Periodicals Review as a winner of the VanArsdel Prize.

Roger Ebbatson is currently Hon Visiting Professor at Lancaster University. His publications include Hardy: Margin of the Unexpressed (1993), An Imaginary England (2005), Heidegger's Bicycle (2006), Landscape \& Literature, 18301914 (2013) and most recently, Landscapes of Eternal Return: Tennyson to Hardy (2016).

John Holmes is Professor of Victorian Literature and Culture at the University of Birmingham. He was the Chair of the British Society for Literature and Science from 2012 to 2015 and is currently Secretary of the Commission on Science and Literature. $\mathrm{He}$ is the author of Darwin's Bard: British and American Poetry in the Age of Evolution (2009; pbk 2013), the editor of Science in Modern Poetry: New Directions (2012), and the co-editor (with Sharon Ruston) of The Routledge Research Companion to Nineteenth-Century British Literature and Science(2017). His next monograph, The Pre-Raphaelites and Science, is due to be published by Yale University Press in 2018.

Jay Labinger is Administrator of the Beckman Institute and Faculty Associate in Chemistry at Caltech. His research interests include organometallic chemistry and energy-related problems in catalysis, history of chemistry, and literary and cultural aspects of science. His books include The One Culture? A Conversation about Science (Chicago UP, 2001), co-edited with Harry Collins, and Up from Generality: 
How Inorganic Chemistry Finally Became a Respectable Field (Springer, 2013). He is a Fellow of the American Association for the Advancement of Science, and a past president of SLSA.

Derek Lee is a doctoral candidate in English Literature at the Pennsylvania State University. His research interests span twentieth and twenty-first century literature, including modernism and the occult, philosophy of science, phenomenology, speculative ethnic fiction, and comics. His dissertation examines the trajectory of the paranormal mind as a historical and epistemological concept in twentieth-century literature and science.

Jennifer L. Lieberman is Assistant Professor of English at the University of North Florida. An interdisciplinary scholar, she holds a Ph.D. in English, completed a National Science Foundation postdoctoral fellowship in science and technology studies, and holds baccalaureate degrees in English and mathematics. Her articles can be found in such venues as Configurations, The Eaton Journal of Archival Research in Science Fiction, History and Technology, MELUS: Multi-ethnic Literature in the US, and Studies in the Novel. Her first book, Power Lines: Electricity in American Life and Letters, 1882-1952, was published by MIT Press in 2017.

Melissa M. Littlefield is an Associate Professor at the University of Illinois, UrbanaChampaign where she has appointments in the Departments of English, Kinesiology and Community Health, and the Beckman Institute for Advanced Technology. Littlefield's work can be found in Frontiers in Human Neuroscience; Social Studies of Science; and Science, Technology \& Human Values. She is the author of The Lying Brain: Lie Detection in Science and Science Fiction (2011) and Instrumental Intimacies: EEG Wearables and Neuroscientific Control (forthcoming, Johns Hopkins University Press). She is co-editor (w/ Jenell Johnson) of The Neuroscientific Turn: Transdisciplinarity in the Age of the Brain (2012); and co-editor (w/ Rajani Sudan) of Configurations.

Richard Nash is Professor of English at Indiana University. He is the author of several books and articles on eighteenth-century British literature and culture, most recently co-authoring with David Oldrey and Tim Cox The Heath and the The Horse: A History of Racing and Art on Newmarket Heath. He is currently working on two book projects: Anticipating Ecology: Re-reading Eighteenth Century Poetry with New Materialist Philosophy and Breeding Rebellion: A Revisionist Account of the Origins of the Sport of Horse Racing.

Ralph O'Connor is Professor in the Literature and Culture of Britain, Ireland and Iceland at the University of Aberdeen. He is the author of The Earth on Show: Fossils and the Poetics of Popular Science (2007), which won best book prizes from the BSLS and SLSA. His other books include Science as Romance in Victorian Science and Literature, ed. Gowan Dawson and Bernard Lightman (2011-12), Uncommon Contexts: Encounters between Science and Literature 1800-1914 (2013, co-edited with Ben Marsden and Hazel Hutchison), and three books on mediaeval Irish and Icelandic literature and legend. He is currently completing a monograph on legendary fiction and nonfiction in mediaeval and modern Iceland and a new edition of Hugh Miller's The Old Red Sandstone (with Michael A. Taylor). 
Laura Otis is Samuel Candler Dobbs Professor of English at Emory University. With an MA in Neuroscience and a $\mathrm{PhD}$ in Comparative Literature, she compares the creative thinking of scientists and literary writers. Otis is the author of Organic Memory, Membranes, Networking, Müller's Lab, and Rethinking Thought; the translator of Santiago Ramón y Cajal's Vacation Stories; and the editor of Literature and Science in the Nineteenth Century. Her book in progress, Banned Emotions, analyzes metaphors for socially discouraged emotions such as self-pity. For her interdisciplinary studies of literature and science, she received a MacArthur Fellowship in 2000.

Sally Shuttleworth is Professor of English Literature at the University of Oxford, and PI on the AHRC-funded project, 'Constructing Scientific Communities: Citizen Science in the 19th and 21st Centuries' (www.conscicom.org). She has published extensively on the inter-relations of Literature and Science, including George Eliot and Nineteenth-Century Science (1984), Charlotte Brontë and Victorian Psychology (1996), and The Mind of the Child: Child Development in Literature, Science and Medicine, 1840-1900 (2010). She previously directed the Science in the NineteenthCentury Periodical Project (www.sciper.org), and is currently PI on the ERC project, 'Diseases of Modern Life: Nineteenth-Century Perspectives' which can be found at www.diseasesofmodernlife.org.

Susan M. Squier is Brill Professor Emerita of Women's, Gender and Sexuality Studies and English at Penn State University. Her books include Epigenetic Landscapes: Drawings as Metaphor (Duke UP, 2017), Graphic Medicine Manifesto; Babies in Bottles: Twentieth-Century Visions of Reproductive Technology; Liminal Lives: Imagining the Human at the Frontiers of Biomedicine; and Poultry Science, Chicken Culture: A Partial Alphabet, which was winner of the Michelle Kendrick Prize of the SLSA in 2011. She co-edits the Graphic Medicine book series at PSU Press and collaborates on the PathoGraphics Project, as Einstein Visiting Fellow at the Freie Universität, Berlin (2016-2019).

Jayne Thomas is a postdoctoral researcher, specialising in Romantic influences in Victorian poetry. She completed her doctoral thesis, titled "From Allusion to Intertext: Reading Wordsworth in Tennyson, Browning and Hopkins", at Cardiff University in December 2014. She is currently developing her thesis for publication as a monograph. The project is supported by a British Association of Victorian Studies' Research Grant.

Darren N. Wagner is a Humboldt Postdoctoral Research Fellow hosted by the Freie Universität Berlin and supported by the Stiftung Charite and the Berlin Institute for Health. His research is published in the Journal for Eighteenth-Century Studies, Literature and Medicine, and in a collection he co-edited with Raymond Stephanson, The Secrets of Generation: Reproduction in the Long Eighteenth Century (U Toronto P, 2015). Currently he is writing a monograph titled Sexual Feeling: Sensibility, Neurology, and Generation in Britain, c. 1650-1800. Together with Joanna Wharton he is guest-editing a special issue of Journal for Eighteenth-Century Studies on "The Sexes and the Sciences." 
Jo Waugh is a Senior Lecturer at York St John University. Her PhD from the University of York explored the representation of climate theories and meteorology in the Victorian novel. She is also interested in the relationship between climate, contagion, and disease in the period and has an article on the management of rabies in Charlotte Brontë's Shirley forthcoming in Victorian Review.

Joanna Wharton is an Early Career Fellow at Lichtenburg-Kolleg, the Göttingen Institute for Advanced Study in the Humanities and Social Sciences, where she is working on a project entitled "Lines of Exchange: Literature, Friendship and Lunar Empire." Her first monograph, Material Enlightenment: Women Writers and the Science of Mind, 1770-1830, is forthcoming with Boydell \& Brewer (2018). She has essays in the Journal for Eighteenth-Century Studies (Dec 2013) and in William McCarthy and Olivia Murphy (Eds.), Anna Letitia Barbauld: New Perspectives (Bucknell UP: 2013). Together with Darren Wagner she is guest-editing a special issue of Journal for Eighteenth-Century Studies on "The Sexes and the Sciences."

Martin Willis is Professor of English at Cardiff University, Editor of the Journal of Literature and Science and Chair of the British Society for Literature and Science (2015-18). He is the recent editor of Staging Science (Palgrave 2016), and author of Literature and Science (Palgrave 2015). His Vision, Science and Literature, 18701920 (Pickering and Chatto 2011) won both the BSLS Book Prize and the ESSE Cultural Studies Book Prize in 2012. His present research is focussed on the historic and contemporary relationships between the sciences and the humanities and at Cardiff he leads the ScienceHumanities research initiative.

Cary Wolfe is Bruce and Elizabeth Dunlevie Professor of English at Rice University, where he is also founding director of 3CT: The Center for Critical and Cultural Theory. His books include Animal Rites: American Culture, the Discourse of Species, and Posthumanist Theory (2003), What Is Posthumanism? (2010), and Before the Law: Humans and Other Animals in a Biopolitical Frame (2013). He has also participated in multi-author projects involving J.M. Coetzee, Cora Diamond, Stanley Cavell, Paola Cavalieri, and others. Since 2007 he has been founding editor of the series Posthumanities at the University of Minnesota Press, which has published over forty volumes to date. 